
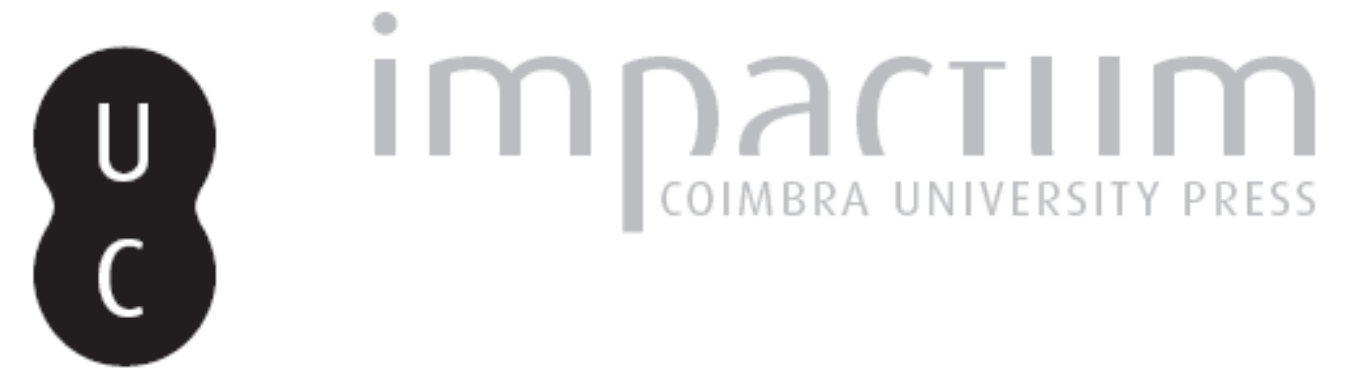

\title{
Goldoni e Inácio de Oliveira Bernardes: um encontro de artistas
}

Autor(es): Brilhante, Maria João

Publicado por: Imprensa da Universidade de Coimbra

URL persistente:

URI:http://hdl.handle.net/10316.2/42638

DOI:

DOl:https://doi.org/10.14195/0870-8584_2_4

Accessed : $\quad$ 26-Apr-2023 14:34:37

A navegação consulta e descarregamento dos títulos inseridos nas Bibliotecas Digitais UC Digitalis, UC Pombalina e UC Impactum, pressupõem a aceitação plena e sem reservas dos Termos e Condições de Uso destas Bibliotecas Digitais, disponíveis em https://digitalis.uc.pt/pt-pt/termos.

Conforme exposto nos referidos Termos e Condições de Uso, o descarregamento de títulos de acesso restrito requer uma licença válida de autorização devendo o utilizador aceder ao(s) documento(s) a partir de um endereço de IP da instituição detentora da supramencionada licença.

Ao utilizador é apenas permitido o descarregamento para uso pessoal, pelo que o emprego do(s) título(s) descarregado(s) para outro fim, designadamente comercial, carece de autorização do respetivo autor ou editor da obra.

Na medida em que todas as obras da UC Digitalis se encontram protegidas pelo Código do Direito de Autor e Direitos Conexos e demais legislação aplicável, toda a cópia, parcial ou total, deste documento, nos casos em que é legalmente admitida, deverá conter ou fazer-se acompanhar por este aviso. 


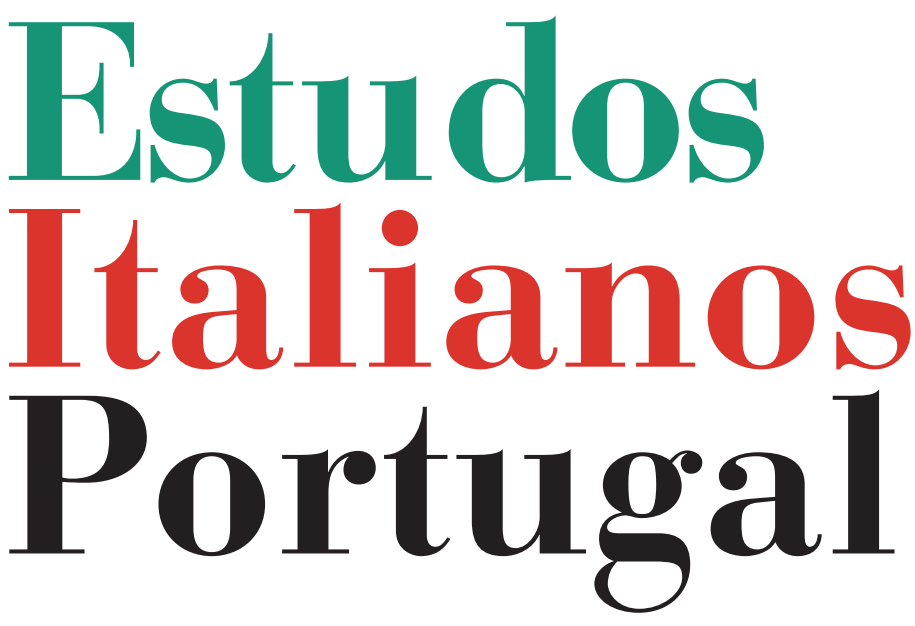

Instituto

Italiano

de Cultura

de Lisboa

Nova Série

$\mathbf{N}^{\mathbf{0}} 2$ 


\title{
GOLDONI E INÁCIO DE OLIVEIRA BERNARDES: UM ENCONTRO DE ARTISTAS
}

\author{
Maria JoÃo Brilhante ${ }^{\star}$
}

ENTRE os vários CAMinhos que se abrem ao estudo da presença da obra de Goldoni em Portugal, um parece particularmente fascinante, provavelmente por ser ainda insatisfatória a informação que possuímos acerca da realidade teatral de setecentos no nosso país, e ser por isso estranha a ligação a um nome consagrado como o do reformador da comédia italiana.

Refiro-me às diversas dimensões de que se revestiu a criação cénica dos textos de Goldoni nos palcos públicos e da corte no período que corresponde à transformação do campo teatral português (anos 60 e 70), estudado recentemente por Maria João Almeida ${ }^{1}$ e a suscitar ainda muita investigação.

Foi a pesquisa sobre o teatro em Portugal no século XVIII e a descoberta dos esboços cenográficos de Inácio Oliveira

* Nasceu em Lisboa em 1956, licenciou-se em Literaturas Românicas pela Faculdade de Letras de Lisboa e é actualmente Professora Associada nessa Faculdade, leccionando Literatura e Cultura francesas, Espaço e Imagem do Teatro e História do Teatro. Desenvolve investigação em iconografia teatral e história do teatro em Portugal. Criou com Osório Mateus, em 1990, a primeira pós-graduação em Estudos de Teatro do país e em 1994 o Centro de Estudos de Teatro, unidade de investigação da Universidade de Lisboa. Fez crítica de teatro no Jornal de Letras e no Público e foi um dos membros fundadores do grupo Produções Teatrais onde se ocupou de produção. Desde 1995 traduz para teatro. Tem publicado artigos em livros e revistas portuguesas e estrangeiras.

1 Maria João Almeida, 2007, O teatro de Goldoni no Portugal de Setecentos, Lisboa: Imprensa Nacional-Casa da moeda. 
Bernardes que me levaram a tentar cruzar as obras destes dois artistas com o intuito de colocar algumas questões ao restauro da prática teatral nesse período. Por isso, o que aqui se expõe é o início da análise dos trabalhos de cenografia realizados pelo referido artista a partir de textos de Goldoni. Esse encontro de artistas corresponde, creio, a um momento de transformação da estética teatral no que se refere à concepção do espaço cénico nos palcos portugueses e daí fazer sentido aproximar os dois criadores.

Não tem sido muito sistemático o estudo dos artistas que trabalharam no teatro e na ópera em Portugal durante o século XVIII. Isso deve-se em grande parte à escassez de documentação recolhida até hoje, sendo comum ficarem os estudiosos pela listagem de nomes e, em alguns casos, por breves notas biográficas que traçam de forma irregular o percurso artístico de cantores, cenógrafos, músicos, autores, tradutores e adaptadores. $\mathrm{Na}$ verdade, dos resultados das suas actividades, pela sua natureza efémera, poucos registos ficaram, o que torna, por isso mesmo, alguns casos merecedores da nossa atenção. Não se deve certamente apenas ao acaso o facto de dispormos de informação interessante sobre o trabalho de Giovanni Carlo Bibiena nos teatros da corte portuguesa, particularmente para a Ópera do Tejo, um acervo razoável e expressivo de imagens e escritos sobre Luisa Todi ou, como veremos, esta colecção de esboços cenográficos de Inácio Oliveira Bernardes. Mas só uma pesquisa aturada permitirá retirar do esquecimento outros criadores, colocando-os no lugar do "puzzle" - que ainda hoje é a história do teatro e do espectáculo em Portugal - que merecem ocupar.

\section{CircunstÂNCIAS DE UM ENCONTRO}

Que sabemos então de Inácio de Oliveira Bernardes e daquilo que o liga a Carlo Goldoni? Nasceu em Lisboa, em 
1695, filho de António Oliveira Bernardes, conhecido como pintor de azulejos. Começou cedo a sua actividade, pois em 1718 já pertence à confraria dos pintores, a Irmandade de São Lucas, e em 1720 parte para a Academia Portuguesa de Roma, criada por D. João V, por lá ficando até ao fecho da mesma em 1725, regressando como arquitecto e pintor em igrejas e conventos (Mafra, Menino Deus, entre outros).

A ligação ao teatro parece existir antes de oficialmente se tornar o arquitecto-cenógrafo do rei D. José I, em 1760, depois da morte de Giovanni Carlo Bibiena. Terá trabalhado para os Congregados do Espírito Santo, que promoveram teatro nos vários locais que ocuparam em Lisboa (Palácio das Necessidades, Belém), e para o Teatro da Rua dos Condes.

Mas dessa actividade nada chegou até nós, o que desde logo permite conjecturar acerca da razão pela qual subsistiram os esboços de que falarei. Na verdade é para a corte que trabalhará até 1767, altura em que Giacomo Azzolini, que fora colaborador de Bibiena, é nomeado "Arquitecto inventor das scenas". Terão talvez continuado a trabalhar juntos nas festas com teatro no palácio de Queluz, pois as contas do palácio indicam despesas associadas a Oliveira Bernardes. Criou com Vieira Lusitano e Cirilo Wolkmar Machado a Academia do $\mathrm{Nu}$, instituição que encontrou resistências para poder funcionar até ficar, em 1785, a cargo do Intendente Pina Manique. A sua ligação ao teatro pode ter passado para segundo plano numa carreira em que se destaca a pintura e a arquitectura, mas não esqueçamos que a efemeridade da arte do teatro contrasta com a perenidade das belas artes. Morre em 1781.

Por estes anos 60, Goldoni está em Paris e é um autor consagrado. A correspondência mantida entre o embaixador português nessa cidade e o Secretário de Estado dá conta da existência de uma ligação à coroa portuguesa que se traduziu na encomenda feita por D. José I de "drammi jocosi" para serem musicados e representados pela companhia de 
ópera do rei. Há noticia de pagamentos pela entrega de pelo menos três óperas, sem indicação dos seus títulos. No entanto, cruzando as notícias publicadas na Gazeta de Lisboa, onde surgem referidos os eventos artísticos ocorridos na corte, com a mencionada correspondência e também com a informação relativa à actividade de Inácio de Oliveira Bernardes como arquitecto e decorador dos teatros régios entre 1760 e $1766^{2}$, percebemos que os dois artistas se encontraram em pelo menos oito produções operáticas, entre 1762 e 1766. São os anos de grande sucesso do reportório operático goldoniano na corte (e mesmo nos teatros públicos), cabendo ao cenógrafo português inventar as vistas para os seguintes libretos:

L'Amore Artigiano [Latilla, Salvaterra, 1762].

Il Mercato di Malmantile [Domenico Fischietti, Salvaterra, Carnaval de 1763].

Il Dottore [Salvaterra, 1763].

Amor Contadino [Giovanni Battista Lampugnani, Salvaterra, Carnaval de 1764].

L'Arcadia in Brenta [João Cordeiro da Silva, Salvaterra, Carnaval de 1764].

Il Mondo della Luna [Pedro António Avondano, Salvaterra, 3 de Fevereiro, Carnaval de 1765 e Queluz, no mesmo ano]. La Cascina [Giuseppe Scolari, Salvaterra, Carnaval de 1766 e Queluz, no mesmo ano].

La Notte Critica [Niccolo Piccini, Salvaterra, Carnaval de 1767]. ${ }^{3}$

2 Existente no Arquivo Histórico do Ministério das Finanças.

3 Joaquim Manuel da Silva Correia e Natália Brito Correia Guedes, O Paço Real de Salvaterra de Magos. A corte. A ópera. A falcoaria, Lisboa: Livros Horizonte, 1989: 42-45, 205-251, 257-263. Segundo Maria João Almeida (2007: 265) são 15 os dramas jocosos para música de Goldoni apresentados quer nos teatros régios, quer públicos entre 1762 e 1791. 


\section{IMAGENS QUE FALAM}

Antes de nos referirmos aos esboços cenográficos de Inácio de Oliveira Bernardes é necessário ter presente que a sua análise e a pertinência para a história do teatro devem exigir alguma prudência, necessária sempre que se aborda o terreno da chamada iconografia teatral. Percebe-se melhor a que me refiro quando se compara uma imagem que ilustra uma das edições (Zatta e Figli, 1795) das obras completas de Goldoni, Il mercato di Malmantile ( $1^{\text {a }}$ representação, Viena, 1757) (Fig. 1) e o esboço cenográfico realizado por Oliveira Bernardes para a produção da mesma comédia em Salvaterra, em 1763 (Fig. 2).

Não obstante as semelhanças, a presença, no primeiro caso, de figuras humanas, o detalhe na representação de um espaço público, a sugestão de acções em curso por contraste com o espaço desabitado e ordenado da segunda imagem, onde a perspectiva central destacando o castelo interfere na percepção do $1^{\circ}$ plano, podem ocultar a diferente funcionalidade de cada uma delas, logo a sua especificidade no complexo campo teatral onde circulam materiais muito diversos, cada um contribuindo a seu modo para a construção da memória do teatro. A primeira imagem sinaliza o teatro através da cortina e da colocação das figuras à "boca de cena", na segunda descobrimos telão de fundo e talvez três bastidores; uma não é registo de um espectáculo, a outra é prefiguração do que será eventualmente o espaço cénico.

Percebe-se, pois, como pode ser sedutor associar indiscriminadamente imagens a espectáculos produzidos a partir de textos de Goldoni: vê-las como representação de teatro ou como modelo para um teatro desejado.

$\mathrm{Na}$ verdade, as imagens falam, mas falam em rede. Relacionam-se umas com as outras e dentro dos códigos estéticos que as conformam: neste caso os do livro ilustrado e os da produção de artefactos para a fabricação do espectáculo. Ao 


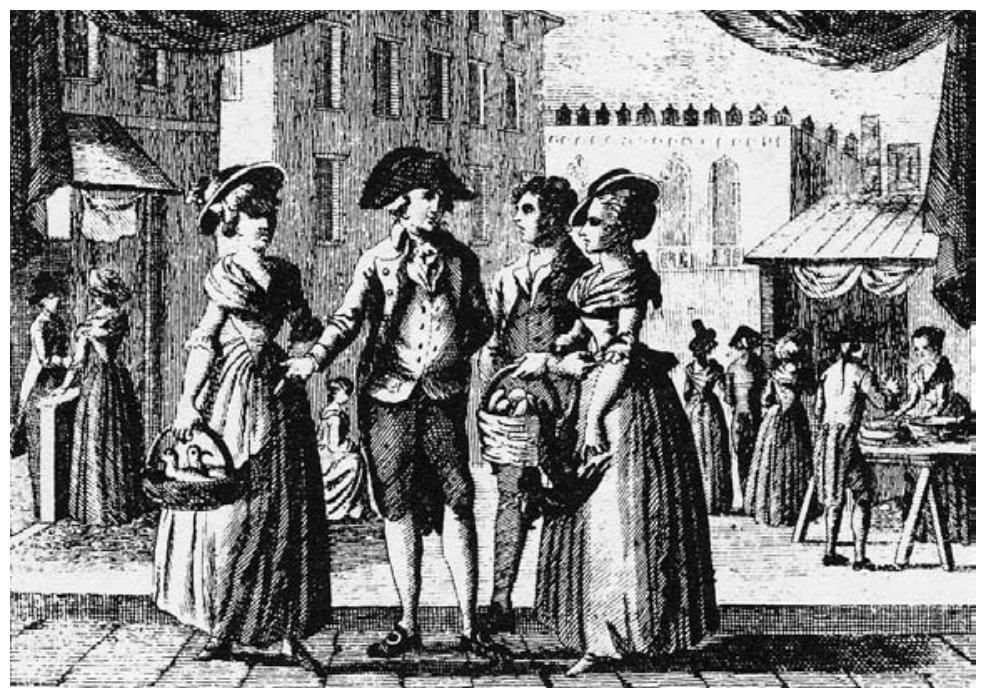

Figura 1 - Il Mercato di Malmantile, Zatta, t. 10, 1795

Fonte: Carlo Goldoni. Il teatro illustrato nelle edizioni del Settecento, int. di Cesare Molinari, Venezia, Marsilio (C. Goldoni, Le Opere, Edizione Nazionale), 1993

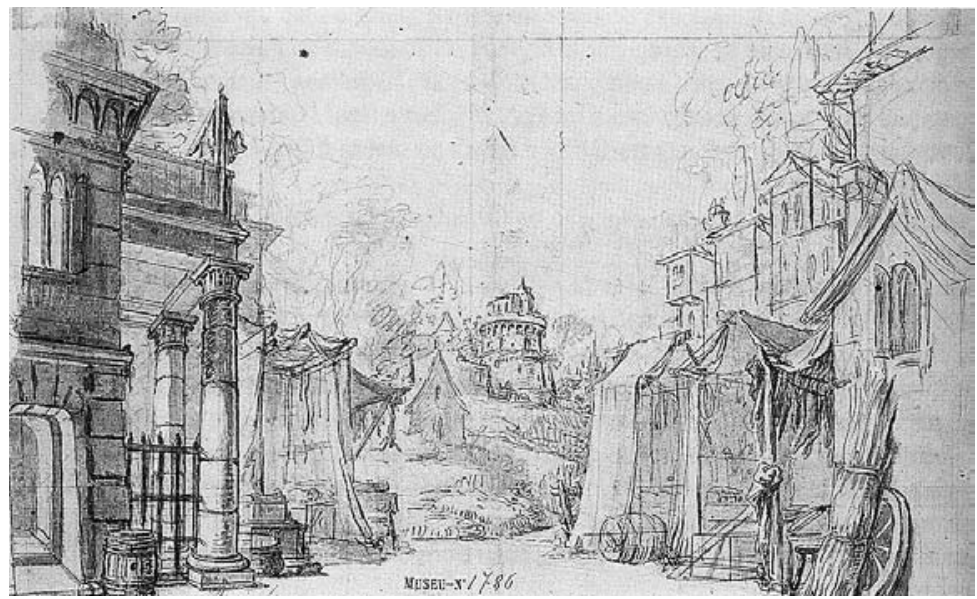

Figura 2 - Estudo cenográfico para Il Mercato di Malmantile

Fonte: Artur Goulart de Melo Borges, "Inácio Oliveira Bernardes arquitecto decorador dos Teatros régios", Doutor Carlos Goldoni veneziano, posto em gosto portuguez, catálogo da Exposição documental e iconográfica no Museu de Évora, 1994 
percorrermos todas as imagens inseridas na referida edição verificamos que as figuras e os objectos pertencem a uma tipologia e procuram ser um compromisso entre uma ideia de teatro (um teatro de interiores, de cenas burguesas e da representação de um real quotidiano) e as condicionantes técnicas, estéticas e comerciais da ilustração e da edição de teatro, dirigidas simultaneamente a quem viu e a quem não viu esse teatro. Para uns funcionando como reportório de situações ficcionais, para outros como surpreendente registo da vida moderna com direito a ascender aos palcos.

Nada nos diz que uma tal cenografia de situações possa corresponder ao cruzamento entre códigos de representação presentes simultaneamente na pintura de género contemporânea (ilustrada por pintores franceses e flamengos e que se especializará nas conhecidas "conversation pieces» de Hogarth), e nas imagens vivas mostradas nos palcos europeus (embora tenhamos de convocar para o nosso estudo as transformações na dramaturgia clássica, o catalizador sucesso de Garrick e da sua companhia, as propostas teóricas de Diderot e Marmontel, por exemplo). Apesar disso, parece-me indiscutível que ambas as artes - belas artes e teatro - participaram da mutação social e ideológica vivida na segunda metade de setecentos e que as imagens, pese embora as suas especificidades de produção e circulação, disso nos falam.

Cesare Molinari ${ }^{4}$ afirmou, a propósito das gravuras que ilustraram as edições goldonianas, que elas não pretendiam documentar as condições técnicas e artísticas da cena teatral setecentista, mas devolver ao observador coevo a imagem que, enquanto espectador, ele tinha do teatro do seu tempo. E é nessa medida que podem ser tão importantes para a história do teatro italiano dessa época. De facto, nelas coexistem dois padrões estéticos - o das belas artes e o do teatro - mas,

4 Cesare Molinari, "Un teatro immaginario per Goldoni”, Carlo Goldoni. Il teatro illustrato nelle edizioni del Settecento,Venezia: Marsilio, 1993, pp. IX-XL. 
mais importante do que isso, através delas é possível restaurar algum sentido que o teatro fazia para uma comunidade.

Prudentemente considera-se, hoje, que as imagens não são apenas documentos sobre o estado de uma arte, sobre as suas circunstâncias estéticas e ideológicas e sobre a sociedade que a promove e acolhe; são monumentos, isto é, invenções artísticas e artefactos que se constituem como criações autónomas. Esta dupla característica não deve ser escamoteada sob pena de nos iludirmos e de inventarmos um teatro que nunca existiu.

\section{Para uma ÓPERA MODERnA, UMA CENA NÃo BARroca}

Que fazer então com estas imagens de Inácio Oliveira Bernardes com proveito para o conhecimento da presença de Goldoni na cena portuguesa? Em primeiro lugar há que pensar que elas não existem isoladamente. Cruzá-las com outras imagens do seu tempo é fundamental para responder a algumas questões. Por exemplo: de onde vinham os modelos, ou seja, que sabemos da cenografia da época em Portugal, mas também em Itália (país de origem da cena barroca na Europa) e em Espanha (cujos modelos teatrais por largos tempos dominaram o teatro feito em Portugal)? A que teatros e públicos se destinavam os cenários de que estes esboços são testemunho? Que nos dizem sobre a relação do artista com as exigências da produção e da recepção? Em que medida existe uma dependência destes esboços aos textos de Goldoni (o que implica conhecer a restante produção artística de Oliveira Bernardes e, nela, a cenografia concebida para outros textos de outros autores)?

Não é este o lugar para tentar responder a todas estas questões, mas tentarei desenhar os contornos de um universo ainda impreciso por falta de dados, nomeadamente iconográficos. 
Sabemos que até 1755 existiu um pátio de comédias junto à rua da Betesga, o Pátio das Arcas, que foi sofrendo transformações desde o final do século XVI e talvez já não se assemelhasse, nessa data, exactamente aos originais espaços onde pontificou a comédia espanhola. Foi aí que se instalou inicialmente a companhia italiana de Paghetti. Trazia um cenógrafo, Colonelli, que terá adaptado ao palco existente a cena de bastidores, ao que se julga já antes utilizada no teatro produzido pelos jesuítas, pois tiveram ao seu serviço Baccarelli (1719). Parece que também Servandoni por cá passou (1746) ao serviço da corte de João $\mathrm{V}^{5}$.

Quando Giovanni Carlo Bibiena chega a Lisboa, em 1752, vem para dirigir a construção dos teatros nos quais D. José I deseja ver representadas óperas sérias com libreto de Metastasio, apetrechados para a criação cénica dos locais já tipificados da ópera barroca em voga pela Europa e para responder às exigências técnicas do seu funcionamento: grandes aposentos de palácios, salas de trono, acampamentos de guerra, espaços de que as mutações inscritas nos programas das óperas que chegaram até nós (Alessandro nell'Indie, La Clemenza di Tito, L’Olimpiade) dão conta. Será este o reportório dos teatros da corte em Salvaterra e na Ópera do Tejo de curta vida. Após o terramoto desaparece esse projecto de teatro áulico ao serviço da imagem de um reino que deseja emparceirar com as cortes da Europa e para isso se apetrechou dos meios necessários: cantores (entre os quais o famoso Gizzielo), um arquitecto-cenógrafo da célebre família Bibiena, um teatro de ópera feito de raiz, reportório internacional com Metastasio e Goldoni, bailarinos e músicos italianos e compositores como Piccinni, Jomelli ou David Perez, entre outros). Uma inflexão no programa do rei para a produção de dramas com música demorará alguns

5 Encontra-se essa informação em Ayres de Cravalho, Catálogo da colecção de desenhos da Biblioteca Nacional de Lisboa, 1977, p. XXVI. 
anos até à descoberta da "ópera bufa que dominava há mais de uma década o panorama do teatro musical cómico em muitas capitais da Europa."6

Para além da proximidade da corte à estética do barroco bolonhês por via da princesa Mariana Vitória e da casa de Aústria, o modelo italiano servia de forma consistente um programa estético e político de alcance internacional e será nesse contexto que devemos situar ainda o encontro entre Goldoni e Inácio Oliveira Bernardes. Este representaria, depois do terramoto e depois de Bibiena, a continuidade da cenografia italiana na corte, tanto mais que fez a sua formação em Itália e que conheceu de perto o trabalho de Bibiena. No entanto, a sua contribuição talvez signifique mais do que uma mera continuação da estética barroca, de que provavelmente Azzolini seria melhor representante ${ }^{7}$, para nos dar a ver a transição para uma cenografia neo-clássica ou protoromântica. Um estudo comparativo dos esboços cenográficos destes três artistas elucidaria talvez, como afirmei noutra ocasião, a existência simultânea de pelo menos duas estéticas teatrais que marcam, na ópera, o final de um período breve de predomínio da representação de uma arquitectura palaciana sumptuosa continuando em cena a imagem da(s) cortes(s) absolutista(s), para uma arquitectura à escala humana inserida numa natureza idealizada e domesticada, que assenta na decoração e na citação lúdica de motivos clássicos. Basta ver a totalidade de esboços classificados como cenográficos atribuídos a Oliveira Bernardes que existem na Biblioteca Nacional para entender como eles partilham elementos decorativos com os palácios de burgueses nobilitados e de

6 Maria João Almeida, op. cit., p. 155.

7 Veja-se esboço cenográfico de "L’Emiva" ou, como crê Ayres de Carvalho, "Armida" ou "Armida abbandonata" de Jommelli (Teatro de Salvaterra, 1773), (esboço referido no Catálogo da colecção de desenhos da Biblioteca Nacional de Lisboa, 1977, p. 70, com a cota D.183 P.), representando acampamento com várias tendas em perspectiva. 
alguns nobres mais sensíveis à política económica de Sebastião José de Carvalho e Melo: colunas, obeliscos, estátuas e bustos, varandins, balcões com balaústres, vasos, nichos, cascatas decoradas com frutas, flores e animais exóticos etc. Esta óbvia ligação entre as artes, revelando uma sintonia de gosto entre as elites, remete para uma modificação que está tendo lugar na sociedade portuguesa e à qual se adequam os valores e os ambientes contemporâneos representado nos libretos de Goldoni.

A hipótese que aqui se coloca é a de que contribuição de Goldoni terá sido a vários títulos importante para esta modificação. Contrastando com a ópera séria, centrada em efeitos cénicos e acções heróicas, trata-se de uma ópera cómica, projectada para a representação "realista" de conflitos que transmitam os valores de uma nova ordem moral e social.

Em traços gerais podemos dizer que a observação dos esboços de Oliveira Bernardes mais seguramente associados a Goldoni, como são os de Amor Contadino (Fig. 3) e L'Arcadia in Brenta (Fig. 4), mostra duas tendências: a persistência da arquitectura palaciana, contudo sem a elaboração barroca trazida para Portugal por Giovanni Carlo Bibiena, optando antes por um programa neo-clássico (que estará presente também na arquitectura civil e religiosa) onde se introduz uma dimensão humana (as varandas, o mobiliário rocaille", a sugestão de espaços interiores por onde a acção se desdobra); e o elogio da natureza como local ameno, por contraste com a imponência dominadora do palácio régio.

Mas esses esboços não são apenas testemunho de novo programa estético; estão ao serviço da fabricação de um espectáculo, propondo soluções para a concretização plástica e tridimensional de uma acção contida num libreto. Alguns mostram o seu inacabamento, destinados pelo cenógrafo aos executantes, incluindo anotações em italiano de utilidade certa para o estudo do funcionamento da cena (número de 


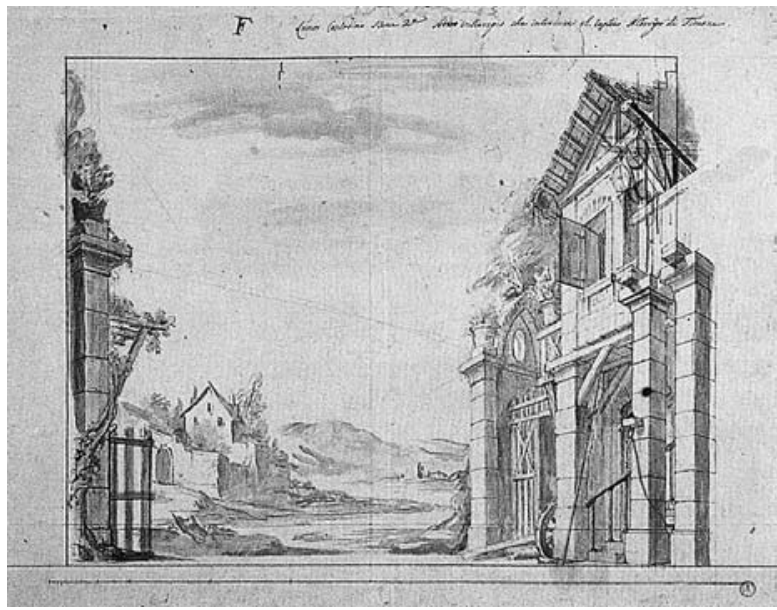

Figura 3 - Estudo cenográfico para L'Amore Contadino

Fonte: Artur Goulart de Melo Borges, "Inácio Oliveira Bernardes arquitecto decorador dos Teatros régios", Doutor Carlos Goldoni veneziano, posto em gosto portuguez, catálogo da Exposição documental e iconográfica no Museu de Évora, 1994

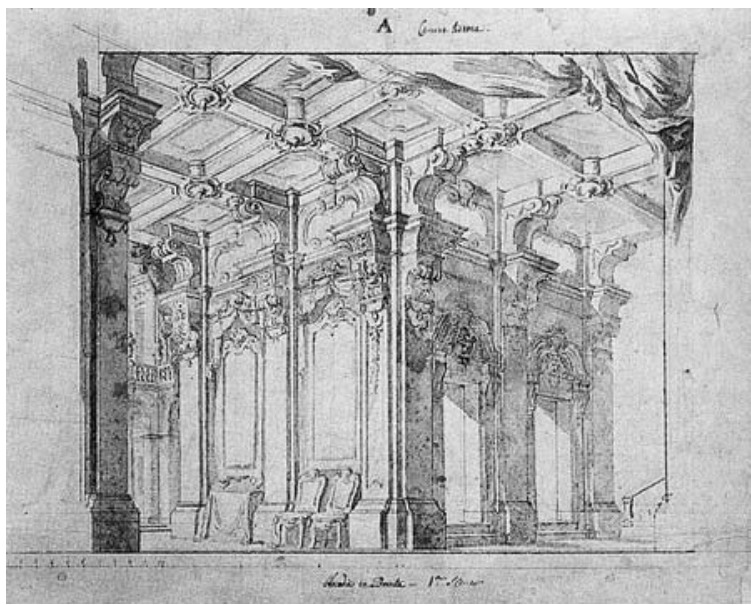

Figura 4 - Estudo cenográfico para L'Arcadia in Brenta

Fonte: Artur Goulart de Melo Borges, "Inácio Oliveira Bernardes arquitecto decorador dos Teatros régios", Doutor Carlos Goldoni veneziano, posto em gosto portuguez, catálogo da Exposição documental e iconográfica no Museu de Évora, 1994 
bastidores, número de mutações, tipologia de materiais etc.). Não foi por certo a sua ligação a Goldoni que os tornou menos efémeros. Mas talvez a possibilidade de virem a ser reutilizados $^{8}$ (a abundante existência de anotações em italiano para servir a execução pode ser forte argumento a favor desta tese) tenha preservado o conjunto que constitui o portfólio do artista (cerca de sessenta esboços).

O caso de Amor Contadino merece, por conseguinte, especial destaque pelo facto de terem chegado até nós quatro esboços e de em todos se verificar a utilização da perspectiva central ou por ângulo para conduzir o olhar do espectador para o ambiente campestre referido no libreto. Ressalvada a liberdade do cenógrafo e a distância a que poderiam os seus esboços estar da concretização cénica, a verdade é que a idealização da paisagem campestre e o seu enquadramento por edificios mais ajustados a ambientes burgueses e aristocráticos contemporâneos falam de um teatro de ópera que entrou em Portugal através dos "drammi giocosi" de Goldoni os quais já nada têm a ver com o "dramma per musica" segundo Metastasio.

$\mathrm{Na}$ imagem em anexo, a fachada da hospedaria é mais do que "cenário": deixa entrever acções humanas através da presença da roda, do guindaste, da janela entreaberta, da mesma forma que o elemento vegetal envolvendo a coluna à esquerda cria uma ligação entre a paisagem pintada e os elementos arquitectónicos. Apesar de vazios de figuras humanas estes esboços são projectados para envolverem personagens que vivem aventuras humanas, conflitos sentimentais que não os transcendem, que os confrontam com os seus caracteres morais e as suas condicionantes sociais.

8 Os cenários de Bibiena para a ópera Demétrio com libreto de Metastasio e música de Schiassi ainda existiam em 1766 (Salvaterra, música de David Perez), como se percebe pela legenda inscrita no esboço produzido por Inácio de Oliveira Bernardes: " $N^{\circ} 2^{\circ}$ que se trocava pelo de Bibiena no Demetrio". 
Os dramas jocosos para música de Goldoni encontraram em Inácio de Oliveira Bernardes, pintor de imagens religiosas, arquitecto de Igrejas e conhecedor da cena barroca, o artista certo para recriar nos palcos régios a realidade contemporânea que a ideologia subjacente à reforma social, económica e política do absolutismo iluminado procura instaurar em Portugal. 